\title{
Protein Levels of Several Arabidopsis Auxin Response Factors Are Regulated by Multiple Factors and ABA Promotes ARF6 Protein Ubiquitination
}

\author{
Keke Li ${ }^{1,2,+}$, Sheng Wang ${ }^{2,+}$, Hong Wu ${ }^{1, *}$ and Hong Wang ${ }^{2, * \mathbb{D}}$ \\ 1 State Key Laboratory for Conservation and Utilization of Subtropical Agro-Bioresouces, \\ College of Life Sciences, South China Agricultural University, Guangzhou 510642, China; \\ kekeli1013@gmail.com \\ 2 Department of Biochemistry, Microbiology and Immunology, University of Saskatchewan, \\ Saskatoon, SK S7N 5E5, Canada; sheng.wang@usask.ca \\ * Correspondence: wh@scau.edu.cn (H.W.); Hong.Wang@usask.ca (H.W.) \\ + These authors contributed equally to this work.
}

Received: 25 October 2020; Accepted: 8 December 2020; Published: 11 December 2020

\begin{abstract}
The auxin response factor (ARF) transcription factors are a key component in auxin signaling and play diverse functions in plant growth, development, and stress response. ARFs are regulated at the transcript level and posttranslationally by protein modifications. However, relatively little is known regarding the control of ARF protein levels. We expressed five different ARFs with an HA (hemagglutinin) tag and observed that their protein levels under the same promoter varied considerably. Interestingly, their protein levels were affected by several hormonal and environmental conditions, but not by the auxin treatment. ABA (abscisic acid) as well as $4{ }^{\circ} \mathrm{C}$ and salt treatments decreased the levels of HA-ARF5, HA-ARF6, and HA-ARF10, but not that of HA-ARF19, while $37^{\circ} \mathrm{C}$ treatment increased the levels of the four HA-ARFs, suggesting that the ARF protein levels are regulated by multiple factors. Furthermore, MG132 inhibited the reduction of HA-ARF6 level by $\mathrm{ABA}$ and $4{ }^{\circ} \mathrm{C}$ treatments, suggesting that these treatments decrease HA-ARF6 level through 26S proteasome-mediated protein degradation. It was also found that ABA treatment drastically increased HA-ARF6 ubiquitination, without strongly affecting the ubiquitination profile of the total proteins. Together, these results reveal another layer of control on ARFs, which could serve to integrate multiple hormonal and environmental signals into the ARF-regulated gene expression.
\end{abstract}

Keywords: abscisic acid; Arabidopsis; auxin response factor; ARF6; protein level; protein ubiquitination; temperature stress

\section{Introduction}

The auxin signaling cascade from auxin perception to activation of auxin-inducible genes has several core components including an SCF (SKP1-Cullin1-F-box) E3 complex, Aux/IAA and ARF (Auxin Response Factor) transcription factors [1]. The binding of auxin to the receptor from the TIR1/AFB (Transport Inhibitor Response and Auxin F-Box protein) family of F-box proteins stabilizes the interaction between the SCF ${ }^{\mathrm{TIR} 1 / \mathrm{AFB}} \mathrm{E} 3$ complex and transcription repressor Aux/IAA proteins, triggering the ubiquitination and degradation of Aux/IAAs. The degradation of Aux/IAA proteins frees ARFs which can bind to the auxin response elements in the promoters of auxin inducible genes and activate their expression [1,2]. Thus, auxin functions essentially through ARFs.

In land plants, $A R F$ genes have evolved into three conserved A, B, and C classes or subfamilies [3]. The Arabidopsis genome encodes 23 ARF genes, but ARF23 is a truncated pseudogene [4,5]. Based on the reporter activation assays in transfected protoplasts, ARFs in Class A are considered as transcriptional 
activators and ARFs in Class B as repressors [6,7]. Class C-ARFs are also considered as transcriptional repressors based mainly on their lack of a glutamine-rich middle region which is important for transcriptional activation [8]. In Arabidopsis, five ARFs (ARF5, 6, 7, 8, and 19) are considered as transcription activators while the others as repressors in Class B and C [4,9]. However, evidence for the majority of the repressor ARFs to function as transcription repressors remained to be obtained $[5,9]$. Since much of the understanding on ARFs has been gained using Arabidopsis as a model, when we describe a specific ARF here it usually refers to the Arabidopsis gene or protein unless a plant species is specified otherwise.

Most ARFs possess three functional domains, an N-terminal DNA binding domain (DBD), a middle region (MR), and a C-terminal PB1 domain [2]. The conserved DBD at the N-terminus is responsible for binding the auxin responsive element $[6,10]$. The transactivator ARFs in Class A contain a glutamine-rich middle region important for transcriptional activation, which is missing in Class C-ARFs [7,8]. The PB1 domain (formerly referred to as domain III/IV) mediates homo- and hetero-oligomerization with Aux/IAAs and ARFs [11-13].

The interactions of ARFs with the Aux/IAA proteins are an important aspect of auxin signaling and its regulation. Since one ARF can interact with multiple Aux/IAAs and vice versa, there is a complex web of interactions among different ARFs and different Aux/IAAs [14]. Results from the yeast two-hybrid studies have shown that the activator ARFs (ARF5, 6, 7, 8, and 19) have more interactions with Aux/IAA proteins compared with the repressor-type ARFs $[15,16]$. Since the levels of protein expression for various ARFs and Aux/IAAs may differ between the yeast system and plants, and also the tissue specificity is missing in the yeast system, it remains to be seen to what extent the interactions observed in the yeast system reflect the ARF-Aux/IAA interactions in plants. In addition, ARFs can interact with other transcriptional factors. For instance, ARF4 interacts with the transcription factor KAN4 that has an important role in ovule development [17] and ARF8 interacts with a transcription factor named BPEp to limit petal growth [18]. Further, ARF6 is found to interact synergistically with the light/temperature-regulated transcription factor PIF4 and the brassinosteroid-signaling transcription factor BZR1 to regulate large numbers of target genes, while the gibberellin-inactivated repressor RGA blocks their DNA-binding activities [19], revealing more complex interaction among the transcription factors.

Most of the information regarding the functions of ARF genes has been obtained using arf mutants $[4,5,20]$. Due to the functional redundancy among the closely related $A R F$ genes, the majority of single mutants for 18 Arabidopsis $A R F$ genes did not show obvious phenotypical changes [21], although single mutants of $A R F 2, A R F 3, A R F 5, A R F 7$, and $A R F 8$ displayed phenotypes revealing the functions in several aspects of plant growth and development [22-25]. For instance, ARF5 functions in the establishment of vascular and body patterns in embryonic and post-embryonic development [24]. In the arf7/nph4-1 mutant, the expression of auxin-responsive reporter genes was much reduced in transfected mesophyll protoplasts which could only be partially restored by other $A R F$ s, suggesting that $A R F 7$ has a major role in regulating a subset of genes in mesophyll cells [26]. Results from various studies using double and multiple mutants helped to identify many different functions of $A R F \mathrm{~s}$ particularly for the Class-A ARFs (ARF5 to 8 and ARF19) [5,20]. For instance, ARF6 and ARF8 have been found to function in adventitious root formation [27], hypocotyl elongation $(A R F 6,7$, and 8) [28] and flower organ development and maturation [29,30], while ARF7 and ARF19 are involved in the regulation of phosphate starvation response [31]. In addition, ARF1 and ARF2 of Class B have a role in regulating senescence and floral organ abscission [32]. ARF2 also functions together with a transcription factor (PLT1) and an auxin transporter PIN1 to control ABA-mediated root meristem activity [33]. Furthermore, ARF10 of Class C is found to be important for root cap formation [34], in vitro callus initiation and shoot regeneration $[35,36]$. These results demonstrate that ARFs play important and diverse functions in plants.

It is well known that the $A R F$ genes are transcriptionally regulated and different $A R F s$ have different expression levels and patterns in different tissues [4,37]. In one study, the expression of all 
23 ARFs in embryogenesis and primary root meristem was characterized using the promoter: GFP reporter approach [38]. The results revealed complex cell-specific patterns and that different $A R F \mathrm{~s}$ had overlapping expression in different cells. Another systematic analysis using in situ hybridization revealed that 13 Arabidopsis ARFs were expressed in the shoot apex, showing differences in the pattern and level [15]. One commonality among the expressed ARFs is that they tended to be expressed at higher levels in the periphery of the shoot meristem. In addition, $A R F$ transcript levels are also regulated by other mechanisms such as alternative transcript splicing and microRNAs [5,37].

The functions of ARFs are also regulated by posttranslational protein modifications. ARF2 can be phosphorylated by a brassinosteroid (BR)-regulated kinase BIN2, leading to the loss of ARF2 DNA binding and repression activities [39]. ARF2 is also phosphorylated under low potassium stress [40]. ARF2 normally represses the expression of a potassium transporter gene $H A K 5$, and the phosphorylation abolishes ARF2 binding to HAK5 promoter and relieves the repression. In addition, BIN2 has been reported to phosphorylate ARF7 and ARF19, and in contrast to reduce activity of ARF2, ARF7, and ARF19 phosphorylation results in the enhanced transactivation activity, which is attributed to reduced ARF7 and ARF19 interactions with the Aux/IAA repressors [41]. On the other hand, ARF7 is modified with the small ubiquitin-like modifier protein and the sumoylation inhibits the interaction with Aux/IAA3 and affects root branching [42].

In terms of the control of protein stability and degradation, there are only a few reports on the control of ARF1 and ARF2 protein levels. Arabidopsis ARF1 is fast degraded in plants and the degradation is inhibited by MG132, a 26S proteasome inhibitor [43]. In addition, ARF1 degradation is not affected in a CUL1 mutant background and by auxin treatment, suggesting that ARF1 is degraded by the $26 \mathrm{~S}$ proteasome, but the degradation is through a CUL1-independent pathway [43]. It has been reported that ARF2 protein expression driven by the native promoter is decreased by ethylene, which is inhibited by MG132 [22]. On the other hand, ARF2 protein abundance is enhanced by gibberellin (GA) treatment [44]. Recently, ARF6, ARF8, and ARF17 were also shown to be unstable and their levels were enhanced by MG132 [45]. Apart from these studies, there has been little information on the protein-level control of other ARFs and further regarding how different hormonal and environmental conditions affect ARF protein levels. In this study, we investigated the protein expression of several ARFs and observed that their levels are affected by several different conditions. We further demonstrated that ABA treatment promotes the ubiquitination and degradation of ARF6.

\section{Results}

\subsection{Analysis of Five ARF Protein Expression in Transgenic Arabidopsis Plants}

To study protein expression, we prepared the plant expression constructs of several ARFs tagged with the HA (hemagglutinin) epitope. We selected three activator ARFs from Class A, ARF5 (At1g19850), ARF6 (At1g30330), and ARF19 (At1g19220), due to the importance of the activator ARFs in activating auxin-regulated genes, as well as ARF1 (At1g59750) from Class B and ARF10 (At2g28350) from Class C [9] for the study. We used the widely used 35S promoter which is not known to be significantly regulated by auxin or any other hormones, so that we could separate the protein control from the transcriptional control by the native ARF promoters. First, Arabidopsis primary transformants of each construct were analyzed for HA-ARF protein expression by western blotting. Each protein sample was prepared from a pool of independent Arabidopsis transformants (about 25 in each plate) to represent the average level of the HA-ARF protein for these transformants. With the expected molecular size of the $2 \times$ HA tag $(3.0 \mathrm{kD})$ included, the theoretical sizes of HA-ARF1, HA-ARF5, HA-ARF6, HA-ARF10, and HA-ARF19 are 76.7, 102.6, 106.3, 79.7, and $123.6 \mathrm{kD}$, respectively. As shown in Figure 1, no HA-specific band was detected in the wild type and transgenic control of a GFP (green fluorescence protein) line. A full-length HA-ARF protein band was detected in HA-ARF5, HA-ARF6, and HA-ARF19 transformants, while only a strong partial HA protein band was detected in ARF1 transformants and no band was detected in ARF10 transformants. Also, it was noted that the two 
replicate samples were similar to each other for $H A-A R F$ constructs, indicating that the protein samples prepared from a pool of 25 independent transformants effectively represent the average expression level of the construct.

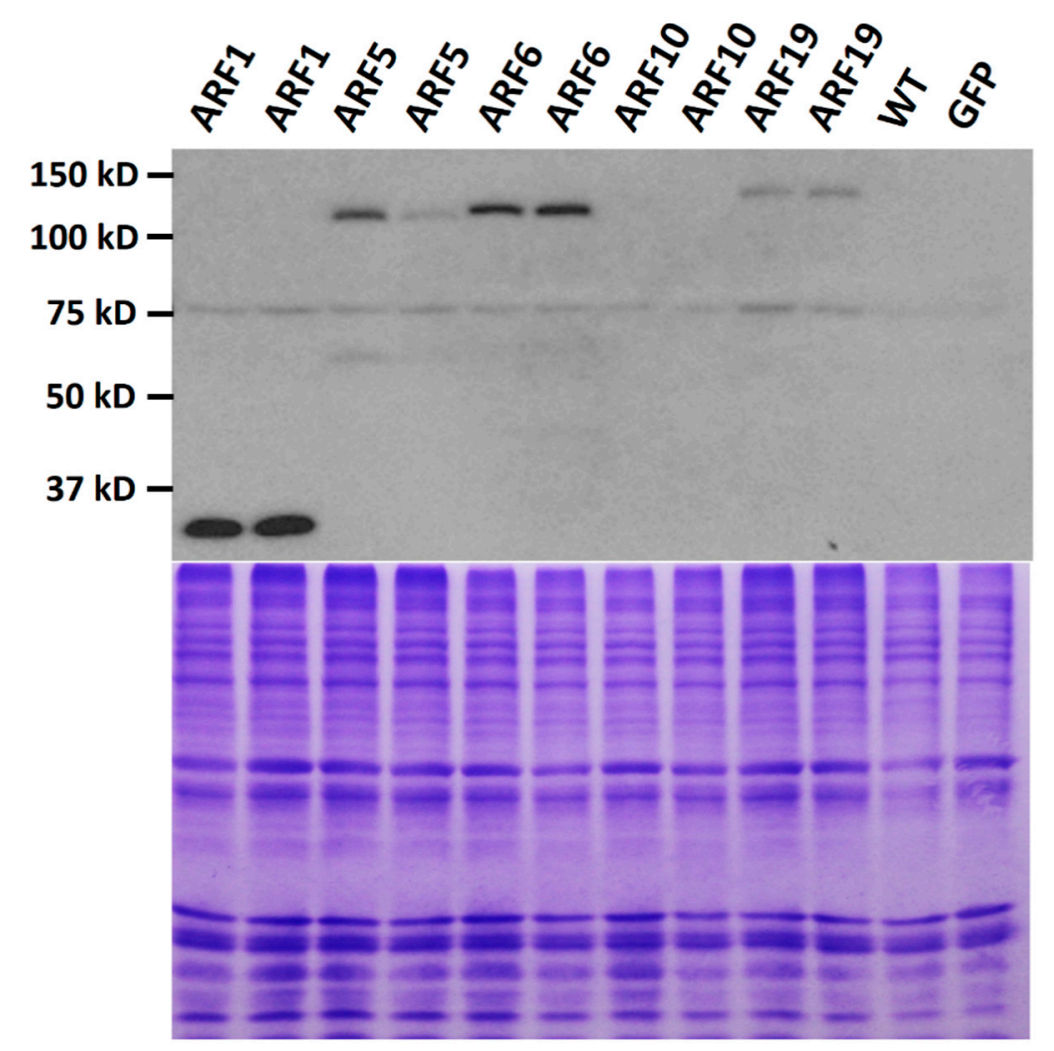

Figure 1. Analysis of HA-ARF protein expression in primary Arabidopsis transformants. Arabidopsis plants were transformed with the HA-tagged ARF constructs. Each protein sample was prepared from a pool of 25 non-selected independent transformants, as well as the control plants, to represent an average expression level for the particular construct. For each construct, two replicate samples were prepared. The protein samples were used for electrophoresis and the HA-ARF fusion proteins were detected by western blotting using an anti-HA antibody. Upper panel: western blotting image, with protein molecular weight markers indicated at the left. There is a weak non-specific band present in all samples. Lower panel: image of the gel stained with Coomassie blue to show the amount of samples loaded.

The purpose of the initial analysis was to determine and compare the protein expression among the five ARFs, using pools of 25 primary transformants. However, the protein level could vary greatly among different transformants. Thus, individual T1 lines were also analyzed. Among at least 12 lines screened for each construct, T1 lines with a full-length HA-ARF protein band was identified for HA-ARF5, HA-ARF6, and HA-ARF19 while lines with only partial band were identified for HA-ARF1 (Figure S1). There were more T1 lines (7 out of 12 lines screened) with the full-length protein for HA-ARF6, consistent with the strongest protein expression level in the primary transformations on average. The initial analysis of HA-ARF10 lines did not identify a line with the full-length protein. Using a commercial gel system and different conditions, three $\mathrm{T} 1$ lines with a full-length protein band were identified (Figure S1). These results collectively indicate that (1) the protein expression level varies greatly among different ARFs when they are driven by the same 355 promoter, with ARF6 having the strongest expression level among the five ARFs analyzed, and (2) ARF1 is easily degraded resulting in only a strong partial HA-ARF1 band detected in some lines. Stable and homozygous transgenic lines of subsequent generations were selected and used in further analysis. 


\subsection{Effects of Hormonal and Environmental Treatments on ARF Protein Expression}

To determine the influence of plant hormones and environmental conditions on ARF protein expression, various hormonal and stress treatments were applied to Arabidopsis seedlings of HA-ARF transgenic lines. After 8 or $12 \mathrm{~h}$ of treatment, protein samples were prepared from treated seedlings and used in western blotting analysis. For HA-ARF6, ABA (abscisic acid) and $4{ }^{\circ} \mathrm{C}$ treatments clearly reduced the protein level in the treated seedlings compared to the controls, while $37^{\circ} \mathrm{C}$ and interestingly 1-aminocyclopropane-1-carboxylic acid (ACC, an ethylene precursor) treatments increased HA-ARF6 level (Figure 2A). The results for HA-ARF5 (Figure 2B) and HA-ARF10 (Figure 2C) are similar. ABA treatment reduced their levels while $37^{\circ} \mathrm{C}$ treatment increased them. Also, $4{ }^{\circ} \mathrm{C}$, $\mathrm{NaCl}$ and mannitol treatments reduced the levels slightly (Figure 2B,C). For HA-ARF19, the protein level remained unchanged for all treatments except for a strong increase by $37^{\circ} \mathrm{C}$ treatment (Figure 2D). Considering all four ARFs together, they share the following similarities: a strong increase by $37^{\circ} \mathrm{C}$ treatment for all four ARFs, a clear decrease by ABA for all but HA-ARF19, and a milder decrease by $4{ }^{\circ} \mathrm{C}$ treatment, $\mathrm{NaCl}$ and mannitol treatments for all but HA-ARF19. The increase by ACC treatment seems specific for HA-ARF6. It is interesting to note that NAA (1-naphthaleneacetic acid) treatment did not affect the protein level of any of the ARFs. There results show that several hormonal and environmental factors instead of auxin can affect ARF protein levels and further their effects may vary among different ARFs.

To further verify the observations, time-course experiments were performed for $\mathrm{ABA}, 37^{\circ} \mathrm{C}$ and $4{ }^{\circ} \mathrm{C}$ treatments on the expression of HA-ARF6. The ABA treatment resulted in a slight reduction in the HA-ARF6 level after $8 \mathrm{~h}$ of treatment and a clear reduction after $12 \mathrm{~h}$ of treatment compared to the control (Figure 3A). For the temperature treatments, seedlings at $37^{\circ} \mathrm{C}$ had a higher level of HA-ARF6 and those at $4{ }^{\circ} \mathrm{C}$ had a lower level of HA-ARF6 after 4 or $8 \mathrm{~h}$ of treatment, compared to the controls (Figure $3 \mathrm{~B}$ ). We further analyzed the treatment effects quantitatively with each treatment having 3-5 replicates. The results showed that HA-ARF6 protein was significantly reduced by $4{ }^{\circ} \mathrm{C}$, and ABA treatments, but significantly increased by $37^{\circ} \mathrm{C}$ treatment (Figure $4 \mathrm{~A}, \mathrm{~B}$ ). The $120 \mathrm{mM} \mathrm{NaCl}$ treatment resulted in a reduction in the HA-ARF6 level, although the reduction was not statistically significant based on the quantitative data. To determine whether the changes in the HA-ARF6 level caused by different treatments were due to a change at the transcript level, RT (reverse transcription)-PCR was performed to detect the HA-ARF6 transcripts using an HA-specific primer and an ARF6-specific reverse primer. The results showed that the HA-ARF6 transcript level remained consistent and was not affected by these treatments (Figure $4 \mathrm{C}$ ). Furthermore, we determined the transcript level by quantitative real-time PCR (qPCR). The results indicated that HA-ARF6 transcript level did not change much when Arabidopsis seedlings were treated under $37^{\circ} \mathrm{C}, \mathrm{ABA}$ and $\mathrm{NaCl}$ conditions, but showed a slight increase at $4{ }^{\circ} \mathrm{C}$ compared to the control (Figure S2). Further examination of the qPCR data (Table S1) revealed that the level of the control gene At4g33380 showed a decrease under $4{ }^{\circ} \mathrm{C}$ treatment and normalization of HA-ARF6 level using At4g33380 resulted in an increase in the HA-ARF6 level. Together, the RT-PCR and qPCR results indicated that HA-ARF6 transcript level did not change much under different treatments and in particular it was not increased by the $37^{\circ} \mathrm{C}$ treatment or decreased by ABA treatment, suggesting that the observed changes in the HA-ARF6 protein level by the treatments are not due to a change in the transcript level, but due to posttranscriptional control on the protein level. 
A

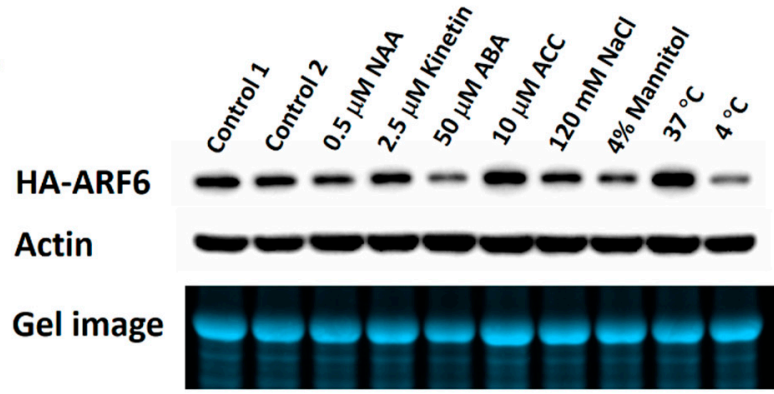

B

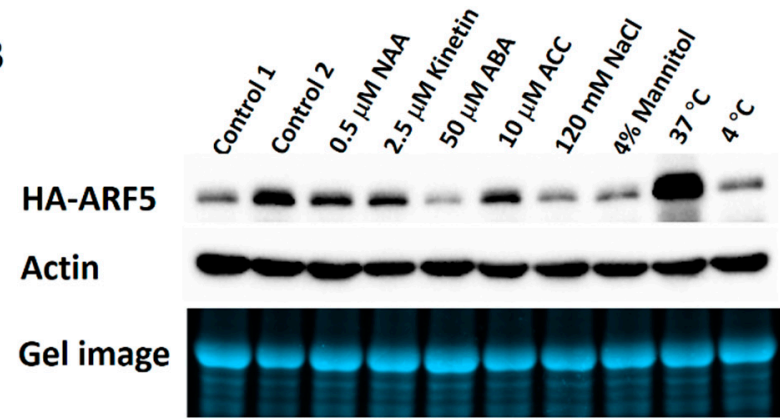

C

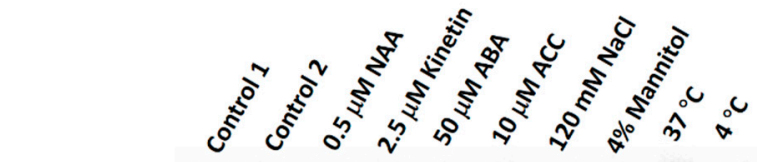

HA-ARF10 - - - - - - -

Actin

Gel image

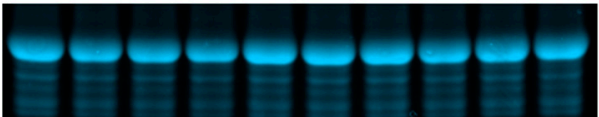

D

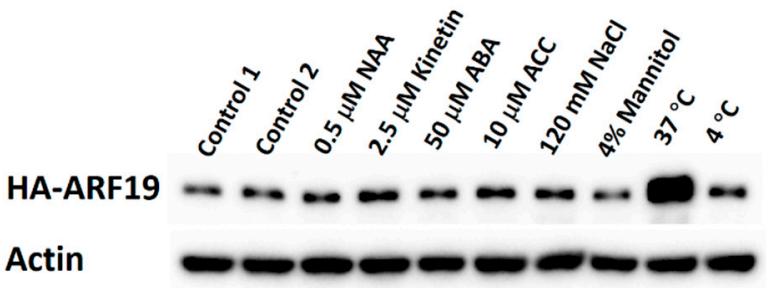

Gel image

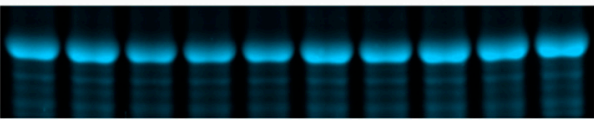

Figure 2. Effects of different treatments on protein expression of HA-ARF6 (A), HA-ARF5 (B), HA-ARF10 (C), and HA-ARF19 (D). Stable transgenic HA-ARF lines (T2 or later generation) were used. Seedlings were grown vertically in Petri plates. At 10 to 11-day stage they were transferred to treatment plates containing a piece of filter paper and $5 \mathrm{~mL}$ half-strength MS with or without a treatment reagent, with each plate having about 25 seedlings. After the treatment, protein samples were prepared and used ( $30 \mu \mathrm{g}$ per lane) for electrophoresis in the Bio-Rad TGX mini-gel, followed by western blotting. In each subfigure, the first row shows the western blot with an anti-HA antibody. For loading controls, the second row shows the western blot with an anti-actin antibody and third row shows the gel image. The treatment conditions are indicated above the lanes. Control 1: half MS medium; Control 2: half MS medium plus $0.1 \%$ ethanol (since NAA, kinetin, ABA were added from ethanol stocks); ACC: 1-aminocyclopropane-1-carboxylic acid. 
A

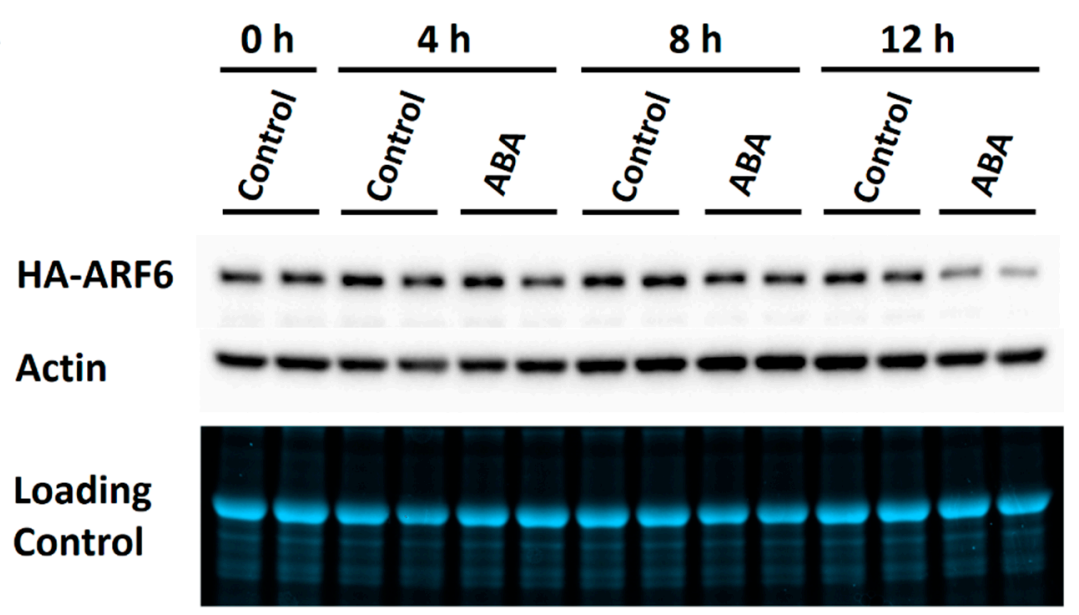

B

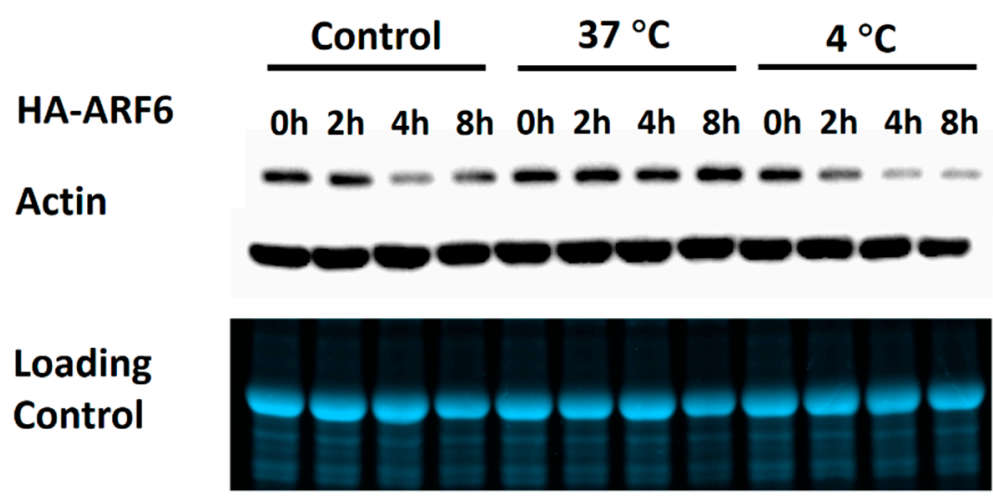

Figure 3. Time-course analysis of ABA and temperature treatments on HA-ARF6 protein levels. Transgenic HA-ARF6 seedlings were grown vertically in Petri plates. For ABA treatments, seedlings (10 to 11-day old) were transferred to treatment plates containing a piece of filter paper and $5 \mathrm{~mL}$ half-strength MS with or without a treatment reagent, with each plate having about 25 seedlings. For temperature treatments, seedlings grown on one-half MS plates were treated directly at the temperatures with the control at $22{ }^{\circ} \mathrm{C}$. After the treatments, protein samples were used for electrophoresis ( $30 \mu \mathrm{g}$ per lane) in the Bio-Rad TGX mini-gel, followed by western analysis. In each subfigure, the first row shows the western blot with an anti-HA antibody, the second row shows the western blot with an anti-actin antibody and the third row shows the gel image. The treatment conditions are indicated directly above the lanes. (A) ABA treatments. Seedlings were treated in control (one-half MS medium plus $0.1 \%$ ethanol) and $50 \mu \mathrm{M}(+$ )-ABA for the indicated hours. Each time point had two replicate samples. (B) Temperature treatments. Seedlings were treated for the indicated hours with the control at $22{ }^{\circ} \mathrm{C}$.

We then examined the effects of ABA and $37^{\circ} \mathrm{C}$ treatments on the protein levels of HA-ARF5, HA-ARF10, and HA-ARF19. As shown in Figure $5,37^{\circ} \mathrm{C}$ treatment of $8 \mathrm{~h}$ strongly increased the levels of HA-ARF5, HA-ARF10, and HA-ARF19 by similar 3-4 folds. The $50 \mu \mathrm{M}$ ABA treatment decreased the levels of HA-ARF5 and HA-ARF10, but not that of HA-ARF19 (Figure 5). Statistical analysis revealed that the changes by ABA treatments were significant for three of the four ARFs except for HA-ARF19. Taken together, those results show clearly that the $37^{\circ} \mathrm{C}$ treatment strongly increases the ARF protein levels, while ABA treatment reduces the levels of HA-ARF5, HA-ARF6, and HA-ARF10, but not HA-ARF19, consistent with earlier observations (Figure 2). 
A

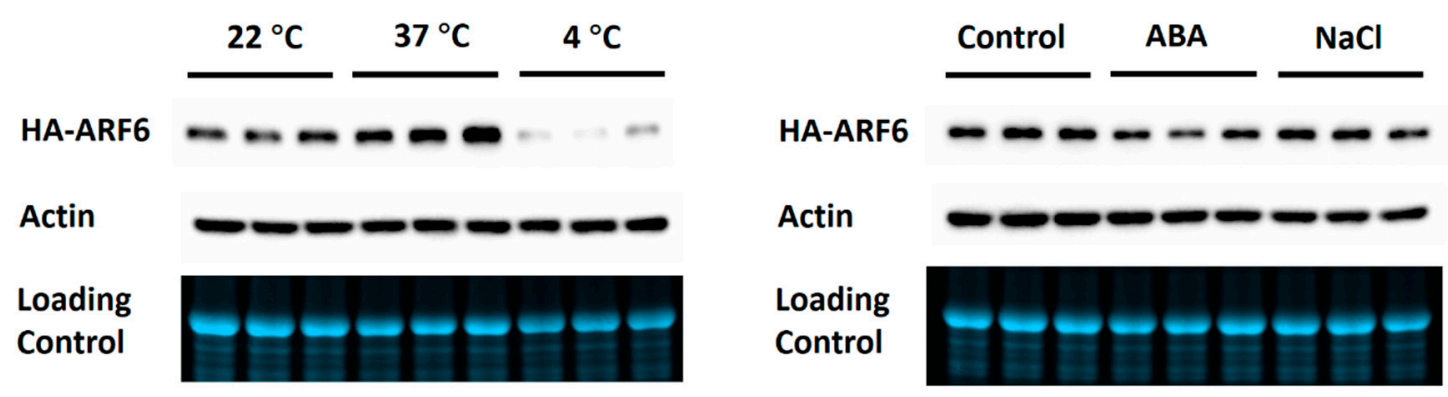

B
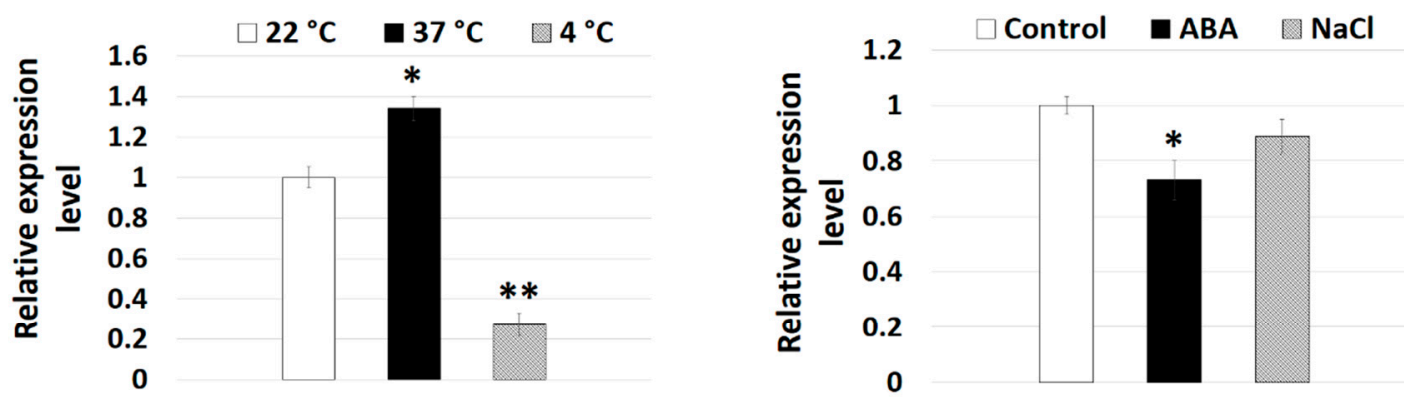

C

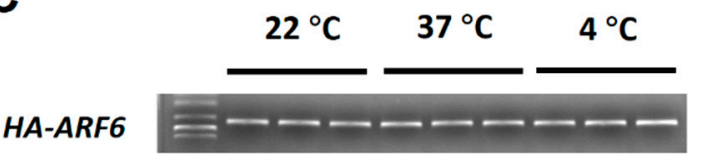

HA-ARF6

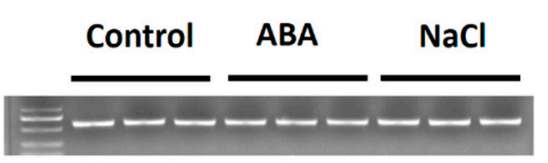

At4g33380

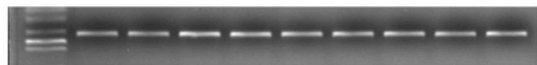

At4g33380

Figure 4. Effects of temperature, $\mathrm{ABA}$, and $\mathrm{NaCl}$ treatments on HA-ARF6 expression. Transgenic HA-ARF6 seedlings were grown vertically in Petri plates. Seedlings (10-day old) were treated directly (for temperature treatments) or transferred to new plates containing a filter paper and $5 \mathrm{~mL}$ half-strength MS with or without the treatment reagent. Each plate had about 25 seedlings. After $8 \mathrm{~h}$ of treatment, protein and RNA samples were prepared. (A) Effects of temperature, ABA, and $\mathrm{NaCl}$ treatments by western analysis (30 $\mu \mathrm{g}$ protein per lane). The first row shows the western blot with an anti-HA antibody. For loading controls, the second row shows the western blot with an anti-actin antibody and third row shows the gel image. The treatment conditions are indicated above the lanes. Left part: temperature treatments. Right part: $(+)-\mathrm{ABA}(50 \mu \mathrm{M})$ and $\mathrm{NaCl}(120 \mathrm{mM})$ treatments. The control had half MS medium plus $0.1 \%$ ethanol. (B) Quantitative analysis of the western blots shown in (A). The intensities of HA-ARF6 bands were measured using Bio-Rad Image software 15.2.1. Student's $t$-test was performed to determine the difference between the treatment and control. For each treatment, the average of three replicates is shown with the standard error. The sign above the bar indicates a significant difference from the control: ${ }^{*} p<0.05,{ }^{* *} p<0.01$. (C) Transcript analysis. RNA samples were isolated from treated seedlings with each treatment having three replicates. cDNAs were synthesized and used in RT-PCR analysis. HA-ARF6 was amplified using a primer specific to the HA sequence and reverse primer for ARF6. The gene $A t 4 g 33380$ was used as a load control. 
A

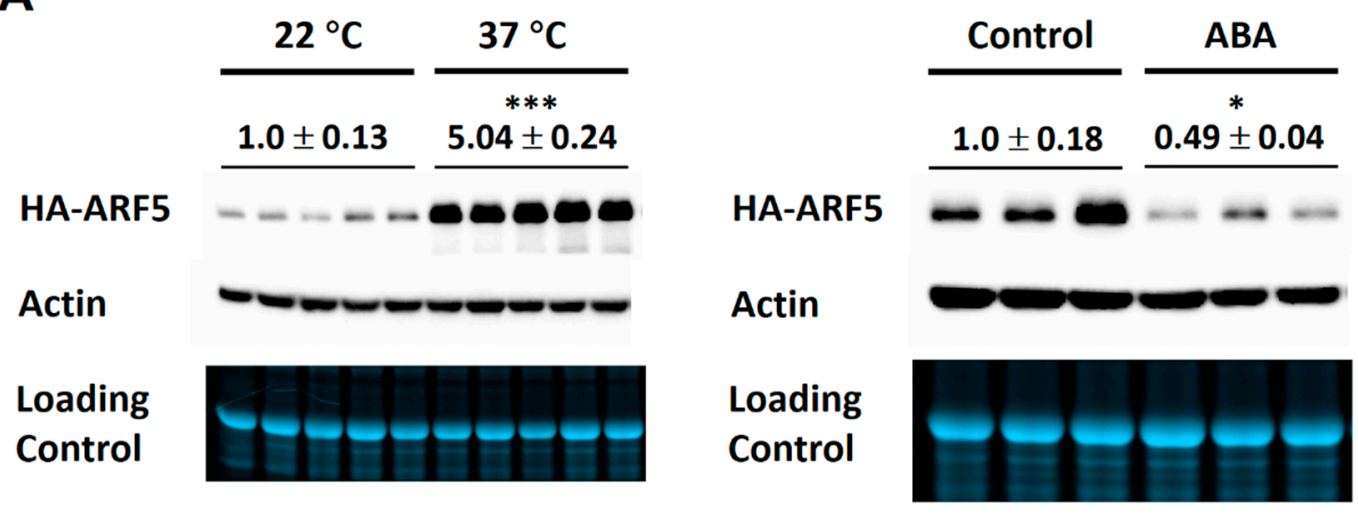

B
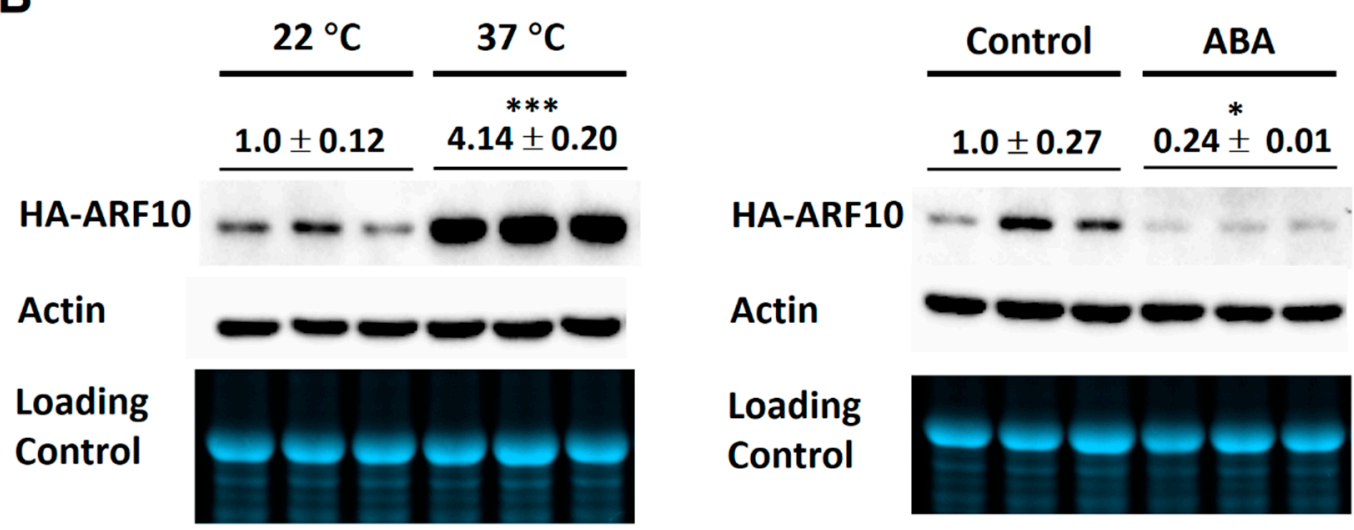

C
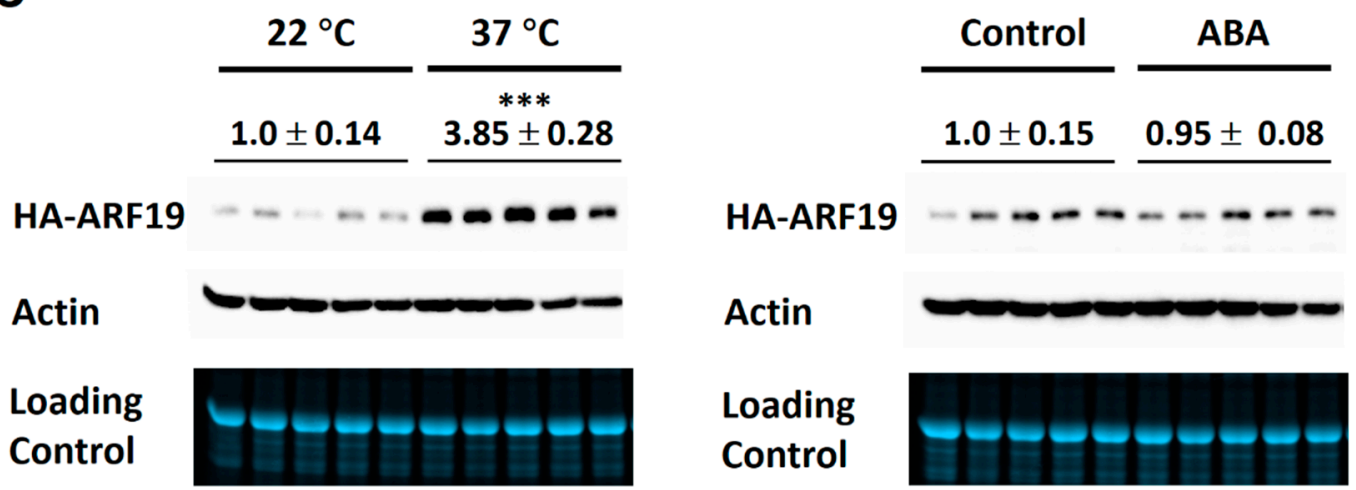

Figure 5. Effects of high temperature and ABA on the expression of ARF5, ARF10, and ARF19. Transgenic seedlings of HA-ARF6, HA-ARF10, and HA-ARF19 were grown vertically in Petri plates. For temperature treatments, seedlings (10-day old) in the plates were treated directly at the indicated temperatures for $8 \mathrm{~h}$. For ABA treatments, seedlings were transferred to new plates containing a filter paper and $5 \mathrm{~mL}$ half-strength MS with or without $50 \mu \mathrm{M}(+)$-ABA. Each plate had about 25 seedlings. After the treatment, protein samples were used (30 $\mu \mathrm{g}$ per lane) in electrophoresis and western blotting. In each subfigure, the first row shows the western blot with an anti-HA antibody, the second row shows the western blot with an anti-actin antibody and third row shows gel image. The treatment conditions are indicated above the lanes, and relative level of ARF protein is shown below the treatment, based on three or five replicates. (A) HA-ARF5. (B) HA-ARF10. (C) HA-ARF19. The controls for ABA treatments used half MS medium plus $0.1 \%$ ethanol. Student's $t$-test was used to determine the difference between the treatment and control. The sign above the average value indicates a significant difference from the control: * $p<0.05,{ }^{* * *} p<0.001$. 


\subsection{Effects of ABA and Temperature Treatments on the Degradation and Ubiquitination of HA-ARF6}

To determine whether the reductions of the HA-ARF6 level by ABA and $4{ }^{\circ} \mathrm{C}$ treatments were through protein degradation, we treated the HA-ARF6 seedlings with or without MG132, an inhibitor of the $26 \mathrm{~S}$ proteasome. Confirming earlier results, ABA and $4{ }^{\circ} \mathrm{C}$ treatments decreased HA-ARF6 level. On the other hand, the seedlings treated with ABA or under $4{ }^{\circ} \mathrm{C}$ in the presence of MG132 had a higher HA-ARF6 level than that of the control (Figure 6A and Figure S3A), suggesting that ARF6 is degraded through $26 \mathrm{~S}$ proteasome. We further performed the $\mathrm{ABA}$ and $4{ }^{\circ} \mathrm{C}$ treatments with or without cycloheximide (CHX), an inhibitor of eukaryotic protein synthesis. The seedlings treated with ABA or under $4{ }^{\circ} \mathrm{C}$ in the presence of $\mathrm{CHX}$ had a lower HA-ARF6 level compared to the treated seedlings without CHX (Figure 6B and Figure S3B), indicating that HA-ARF6 was depleted faster when protein synthesis was inhibited. The observations that HA-ARF6 level was reduced under ABA and $4{ }^{\circ} \mathrm{C}$ treatments, but was increased in the presence of MG132 suggest that $\mathrm{ABA}$ and $4{ }^{\circ} \mathrm{C}$ treatments reduce the HA-ARF6 level by increasing protein degradation through the $26 \mathrm{~S}$ proteasome.

These findings led us to ask whether ABA treatment increases HA-ARF6 protein ubiquitination. To address the question, $\mathrm{ABA}$ and control treatments were applied to the seedlings with or without MG132. Total protein samples were prepared from treated and control HA-ARF6 seedlings. Also, the HA-ARF6 protein was purified by immunoprecipitation using anti-HA-conjugated agarose beads and eluted with HA peptide. The total and purified HA-ARF6 proteins were analyzed by western blotting, with an anti-HA antibody for HA-ARF6 protein and an anti-Ub antibody for the ubiquitinated proteins. For the total protein samples, ABA treatment reduced HA-ARF6 level compared to the control while MG132 increased its level (Figure 7A). The ubiquitinated protein profiles of the total proteins for the ABA and ABA + MG132 treatments were comparable to the two controls, although the ABA + MG132 treatment appeared to have slightly increased amount of protein ubiquitination (Figure 7A, mid-panel, showing a slightly stronger and longer profile). For the purified HA-ARF6 protein samples, ABA treatment sample had a decreased amount of the full-length HA-ARF6 level and the decrease was inhibited by MG132 (Figure 7B). Western blotting of the purified HA-ARF6 samples with the anti-Ub antibody revealed a drastic increase of ubiquitinated proteins in both the ABA and ABA + MG132 samples compared to the controls, suggesting that ABA treatment strongly promotes HA-ARF6 ubiquitination. Furthermore, the band intensity increased with the increasing molecular sizes, suggesting that higher molecular weight proteins with stronger signal may be due to HA-ARF6 protein having increasing number of $\mathrm{Ub}$ moieties (longer poly $\mathrm{Ub}$-chain). It is also interesting to note that although the ABA + MG132 treatment had a higher level of HA-ARF6 than the ABA treatment, the profiles of ubiquitinated proteins for both treatments were similar (Figure 7B, bottom panel), suggesting that although MG132 increased HA-ARF6 level by inhibiting the 26S proteasome activity, it did not significantly affect the abundance of ubiquitinated HA-ARF6 protein under ABA treatment. 
A

A

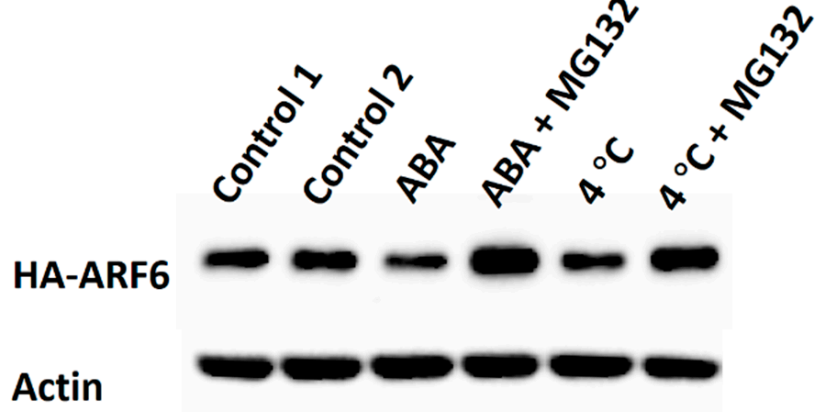

Loading

Control

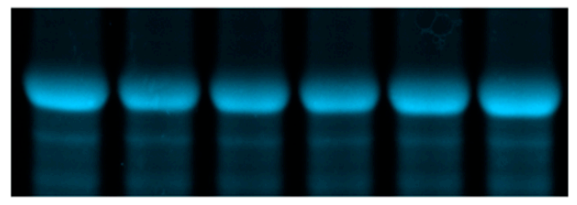

B

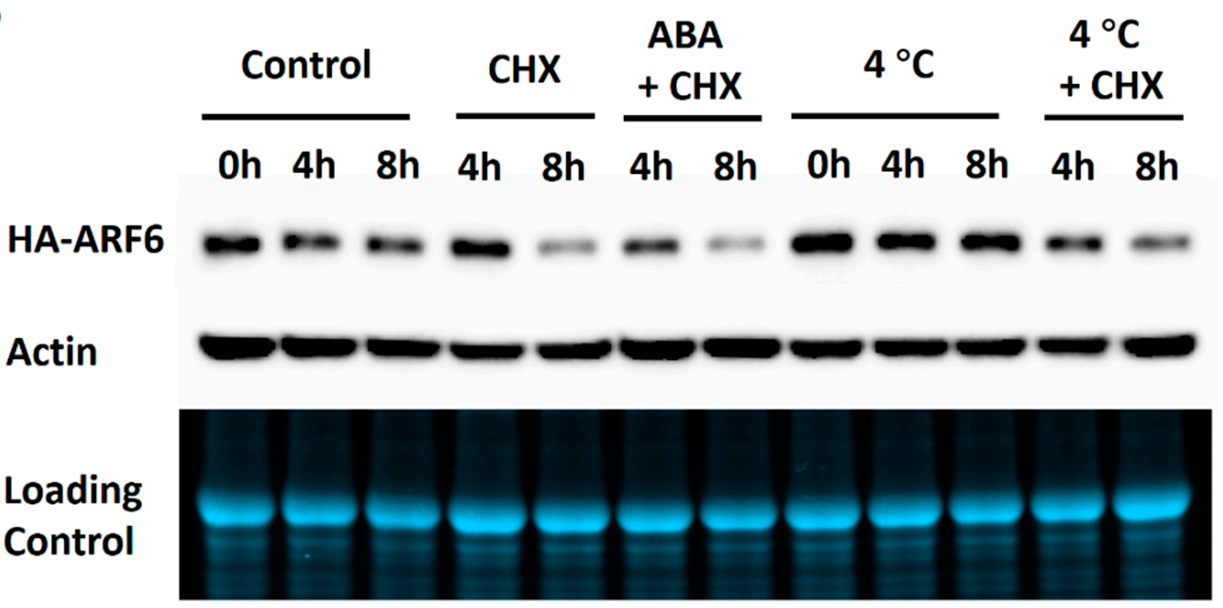

Figure 6. Effects of ABA and $4{ }^{\circ} \mathrm{C}$ treatments on HA-ARF6 level in the presence of MG132 or cycloheximide (CHX). Transgenic HA-ARF6 seedlings were grown vertically in Petri plates. Seedlings (10-day old) were transferred to new plates containing a filter paper and $5 \mathrm{~mL}$ half-strength MS with or without the treatment reagent. Each plate had about 25 seedlings. After 4 or $8 \mathrm{~h}$ of treatment, proteins were extracted and used in electrophoresis ( $30 \mu \mathrm{g}$ protein per lane) in Bio-Rad TGX mini-gels and western blotting. In each subfigure, the first row shows the western blot with an anti-HA antibody. For loading controls, the second row shows the western blot with an anti-actin antibody and third row shows the gel image. The treatment conditions are indicated above the lanes. (A) ABA and $4{ }^{\circ} \mathrm{C}$ treatments with or without MG132. Control 1: normal half MS medium; Control 2: half MS medium plus $0.1 \%$ ethanol and $0.1 \%$ DMSO (ABA and MG132 stocks were prepared in ethanol and DMSO, respectively); $\mathrm{ABA}: 50 \mu \mathrm{M}$; MG132: $25 \mu \mathrm{M}$. (B) ABA and $4{ }^{\circ} \mathrm{C}$ treatments with or without $\mathrm{CHX}$. Control: half MS medium plus 0.1\% ethanol and 0.1\% DMSO; ABA: $50 \mu \mathrm{M}$; CHX: $200 \mu \mathrm{M}$. 
A

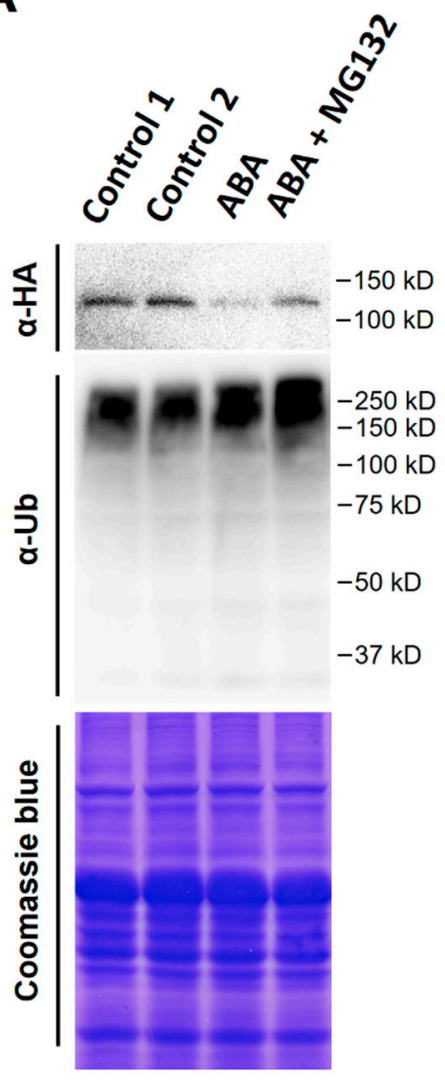

B

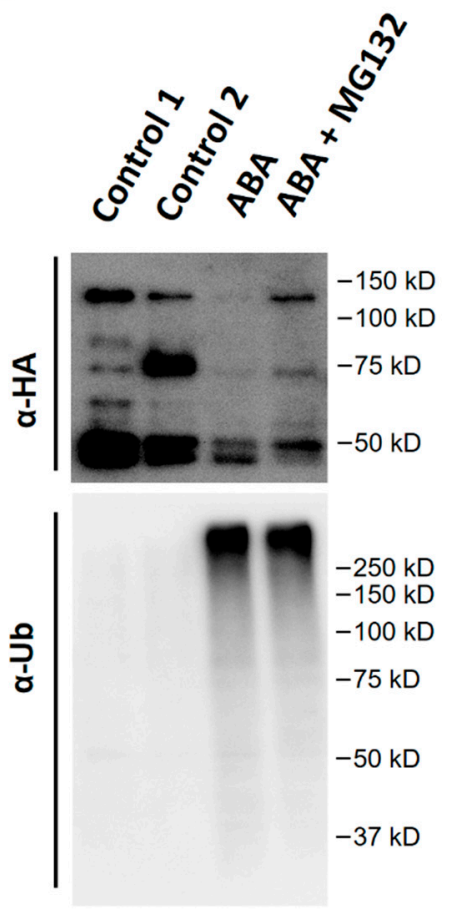

Figure 7. Effect of ABA treatment on the ubiquitination of HA-ARF6. Transgenic HA-ARF6 seedlings were grown vertically in Petri plates. Seedlings (10-day old) were transferred to plates containing a filter paper and $5 \mathrm{~mL}$ half-strength MS with or without the treatment reagent. Each plate had about 25 seedlings. After $8 \mathrm{~h}$ of treatment, protein samples were prepared. (A) Western blotting using total protein samples $(30 \mu \mathrm{g}$ protein per lane). The top panel shows the western blot with an anti-HA antibody, the second panel shows the western blot with an anti-Ub antibody, and the bottom panel shows gel staining with Coomassie blue. The treatment conditions are indicated directly above the lanes. Control 1: normal half MS medium; Control 2: half MS medium plus $0.1 \%$ ethanol and $0.1 \%$ DMSO; ABA: $50 \mu \mathrm{M}$; MG132: $25 \mu \mathrm{M}$. (B) Analysis of purified HA-ARF6. Total proteins (600 $\mu \mathrm{g}$ for each sample) were used to purify HA-ARF6 with anti-HA agarose beads. The purified HA-ARF6 samples were used in western blotting. The top panel shows the western blot with an anti-HA antibody and bottom panel shows the western blot with an anti-Ub antibody.

\section{Discussion}

\subsection{Different ARFs Have Very Different Expression Levels under the Control of the Same Promoter}

Since auxin functions essentially through ARFs and ARFs play important roles in many and diverse plant growth and developmental processes, it is critical to understand how ARFs are regulated. Extensive results have shown that $A R F$ genes are regulated at transcriptional levels and in addition ARF proteins can be modulated through protein modifications such as phosphorylation (see Introduction). However, little is known regarding the control of ARF protein levels. In this study, we investigated ARF protein regulation and how they may be affected by different factors. Furthermore, we used ARF5, ARF6, and ARF19 from Class A, which are the transcription activators, as well as ARF1 and ARF10 which represents Class B- and Class C-ARFs, respectively [9]. The ARFs were tagged with a short HA tag so that the recombinant HA-ARF proteins could be detected conveniently and specifically.

The expression levels of HA-ARF proteins were generally low, even though the strong 35S promoter was used. When groups of primary transformants were analyzed, only HA-ARF5 and 
HA-ARF6 had a clear band while HA-ARF1 and HA-ARF10 were not detected (Figure 1). We had to use a large amount of protein sample to identify T1 transgenic lines expressing the HA-ARF protein (Figure S1). Also, for HA-ARF1, no full-length protein was detected but a strong partial band was observed suggesting that HA-ARF1 was fast degraded. Similarly, it has been shown that Arabidopsis ARF1 is fast degraded in plants and the degradation is inhibited by MG132 [43]. Results from a recent study also indicate that ARF6, ARF8, and ARF17 are unstable proteins [45]. Together, these observations suggest that ARF proteins in general are relatively unstable in plants.

We observed that the protein levels of the five ARFs varied and the three activator ARFs generally had a higher level than the two repressor ARFs. Since the protein samples from the primary transformants were prepared from groups of 25 independent transformants, the HA-ARF level in one protein sample should represent the average expression level of a particular HA-ARF construct, which is supported by the consistency between the two duplicate samples (Figure 1). Since one important molecular property of ARFs is the formation of hetero- and homodimers with Aux/IAA and ARF proteins, protein levels or concentrations in cells are expected to impact the those interactions. Much understanding on ARF and Aux/IAA interactions has been gained using the yeast two-hybrid system in which ARFs are expressed with a yeast promoter. It has been observed that Class A-ARFs interact with more Aux/IAAs than ARFs in Class B and C $[15,16]$. One interpretation is that those ARFs (ARF5 to 8 and ARF19) are able to interact with more Aux/IAA proteins. Alternatively, considering the present findings, the ARFs with fewer interacting Aux/IAA proteins could also be due to a lower protein level.

\subsection{Protein Levels of Four ARFs Are Modulated Posttranslationally by Multiple Factors}

We observed that none of the HA-ARF5, HA-ARF6, HA-ARF10, and HA-ARF19 protein levels under the control of $35 \mathrm{~S}$ promoter was affected by NAA treatment, consistent with previous studies showing that the protein levels of ARF1, ARF2, and ARF7 were not affected by auxin treatments [22,43,44]. The strong increases of the four HA-ARFs by $37^{\circ} \mathrm{C}$ treatment and clear reductions of HA-ARF5, HA-ARF6, and HA-ARF10 by ABA treatment (Figures 2 and 5) suggest that other factors can modulate ARF protein levels independent of auxin. Since the $35 \mathrm{~S}$ promoter is not known to be significantly regulated by plant hormones and temperature, and further we showed clearly that the HA-ARF6 transcript level was not affected by the temperature, $\mathrm{ABA}$, and $\mathrm{NaCl}$ treatments, our results indicate that $\mathrm{ABA}, 4^{\circ} \mathrm{C}$ and $37^{\circ} \mathrm{C}$ treatments modulate the ARF protein levels post-translationally. In addition, the $37^{\circ} \mathrm{C}$ treatment seems to have a stronger effect on HA-ARF5, HA-ARF10, and HA-ARF19 than on HA-ARF6 based on the fold of change (Figures 4 and 5), while ABA treatment had a clear effect on the ARFs except for HA-ARF19, indicating that these factors can affect ARFs differently.

In addition to the clear effects by $\mathrm{ABA}$ and temperature treatments, our results also show that HA-ARF5, HA-ARF6, and HA-ARF10 protein levels were weakly reduced by $\mathrm{NaCl}$ and mannitol treatments (Figure 2). Since it is known that the ABA level increases under stress conditions [46], it is conceivable that $\mathrm{NaCl}$ and osmotic treatments may decrease the ARF protein levels through $\mathrm{ABA}$. Also, the HA-ARF6 level appeared to be promoted by ACC treatment (Figure 2). There has been no report regarding ethylene promoting the protein level of an activator (Class A) ARF. On the other hand, ethylene was found to decrease ARF2 protein level and this effect was inhibited by MG132, suggesting that ethylene promotes ARF2 degradation through the $26 \mathrm{~S}$ proteasome [22]. In addition, it is known that auxin and ethylene have complex interactions, acting synergistically in some processes and antagonistically in others [47]. Thus, it is possible that ethylene may affect the stability and degradation of certain ARFs. Collectively, our results have revealed several factors including ABA, temperature (both high and low temperatures) and salt stress can modulate ARF protein levels and their effects may differ among different ARFs. It will be interesting to investigate how various factors may affect the protein levels of other ARFs. 


\subsection{ABA Treatment Promotes the Ubiquitination and Degradation of ARF6}

There are complex cross-talks among different plant hormones, which are important for plant development and stress response [47-49]. It is thus critical to understand the specific mechanisms that underlie hormone cross-talks. There is some strong genetic evidence on the auxin and ABA interactions. From auxin to ABA direction, it has been shown that the arf10 arf16 double mutant had decreased seed dormancy and lower transcript level of ABI3, an important component in ABA signaling, suggesting that ARF10 and ARF16 may enhance ABA-mediated seed dormancy through the activation of ABI3 [50]. Conversely, ABI3 represses a microRNA (MIR160B) that targets ARF10 and ARF16 [51]. Furthermore, Arabidopsis ARF2 may affect seed size and drought tolerance through regulating ABA signaling [52]. In addition, transgenic expression of a sweet potato IbARF5 in Arabidopsis and downregulation of a tomato SlARF4 have been found to increase ABA content in the plants [53,54]. From ABA to auxin direction, an ABI3-like factor from the bean is known to bind an auxin-inducible promoter [55]. Additionally, Arabidopsis ARF2 expression is induced by ABA treatment and the ARF2 mutants showed enhanced ABA sensitivity in seed germination and primary root growth [56]. Results from those studies indicate that auxin and ABA interact mostly through gene expression and transcript regulation. Our findings that ABA promotes the degradation of several Arabidopsis ARFs and strongly induces the ubiquitination of HA-ARF6. These results indicate that ABA can regulate ARF protein level by promoting their ubiquitination, thus providing a novel link for the ABA and auxin cross-talk.

Also, it is known that cold stress can change auxin transporters and gradient, thus affecting plant growth [57]. Our observation that the $4{ }^{\circ} \mathrm{C}$ treatment promotes ARF6 degradation provides another possible mechanism by which cold stress can affect plant growth. Furthermore, the $37^{\circ} \mathrm{C}$ treatment strongly increased the levels of all four ARFs, while ABA did not have an effect on ARF19. Such differences imply that $37^{\circ} \mathrm{C}$ treatment affects ARFs through a different mechanism from that of ABA. It is interesting to note that NAA treatment did not affect the level of any of the four ARFs analyzed, suggesting that ABA and temperature treatments affect ARF protein levels likely through auxin-independent pathways. It will be important to identify the specific E2 and E3 components responsible for ARF6 ubiquitination and degradation induced by ABA treatment, and investigate the mechanism by which $37^{\circ} \mathrm{C}$ treatment increases ARF protein levels.

\subsection{ARF Protein-Level Control Provides Another Layer of Regulation for ARFs to Integrate Multiple Hormonal and Environmental Signals}

Based on the SCF-Aux/IAA-ARF signaling cascade, auxin functions essentially through ARFs. Experimental evidence so far has shown that ARFs are regulated at several levels (Figure 8). At the transcript level, ARFs are differentially expressed in different cells and tissues (see Introduction). The expression of some ARFs in different plants is regulated by auxin [5]. In addition, the expression of certain $A R F$ s may be regulated by other factors. It has been shown that Arabidopsis ARF19 expression is induced by ethylene [58] and in the root meristem ARF19 is regulated by a cytokinin-dependent transcriptional factor ARR12 [59]. Additional layers of regulation on ARFs include protein modifications and interactions with other proteins [37]. Results in this study reveal another layer of regulation at the protein level, with some factors reducing the protein levels through increased ARF degradation while other factors enhancing ARF levels (Figure 8). Thus, different hormonal and environmental conditions can converge on ARFs through modulating their protein levels and thus affect ARF-regulated gene expression. These results provide strong support for the notion that ARFs may function to integrate multiple signals in addition to their essential role in auxin signaling. 


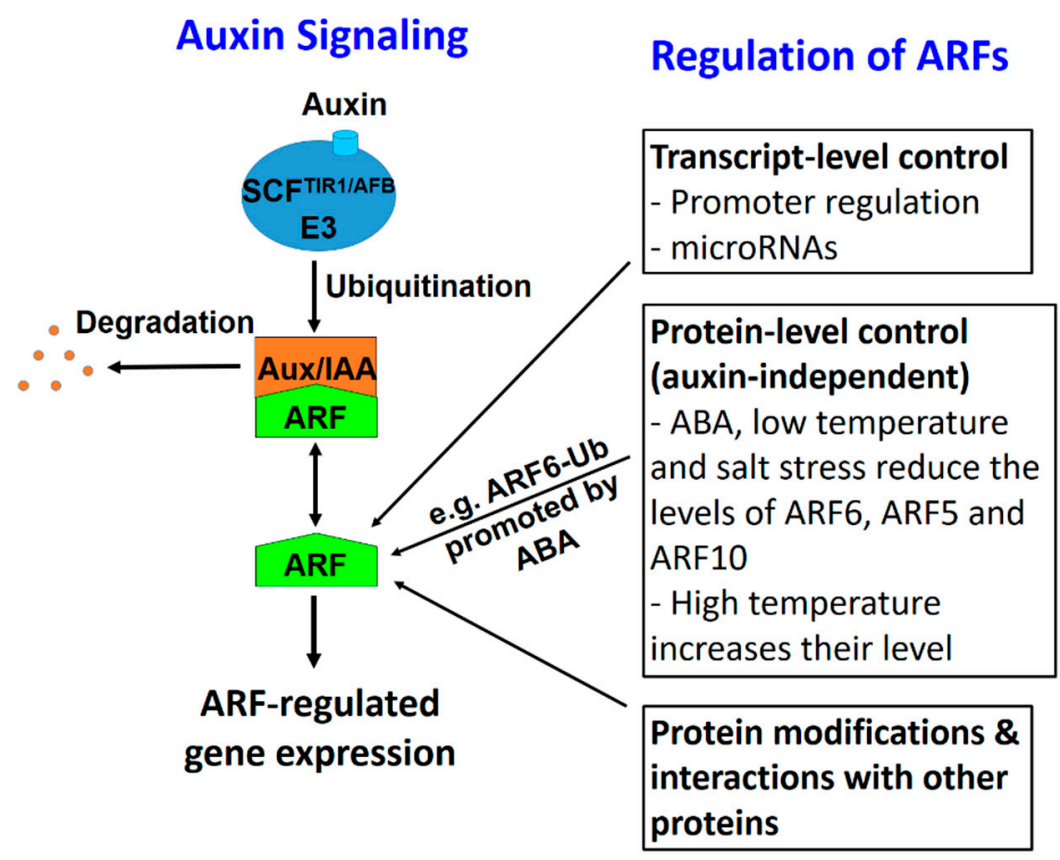

Figure 8. A schematic diagram to show different types of regulation on ARFs, which can integrate multiple signals into the auxin signaling cascade. In auxin signaling, the binding of auxin stabilizes the interaction between the $\mathrm{SCF} \mathrm{FIR}^{\mathrm{TI} / \mathrm{AFB}} \mathrm{E} 3$ complex, resulting in the ubiquitination and degradation of Aux/IAA proteins, which frees ARFs. The ARFs function to activate or suppress ARF-regulated genes. ARFs can be regulated at different levels. Results from this study reveal particularly that several factors can regulate ARF protein levels, likely through auxin-independent mechanisms. ABA, low temperature, and salt stress reduce the levels of certain ARFs while $37^{\circ} \mathrm{C}$ temperature increases their levels. Furthermore, ABA promotes ARF6 ubiquitination.

\section{Materials and Methods}

\subsection{Plant Growth, Construct Preparation, and Plant Transformation}

For normal plant growth and seed harvest, Arabidopsis thaliana ecotype "Columbia-0" WT and transgenic lines were grown in a growth room or chamber $\left(20^{\circ} \mathrm{C}\right.$ constant, $16 / 8 \mathrm{~h}$ day/night photoperiod with a fluence rate of $90-120 \mu \mathrm{moles} / \mathrm{m}^{2} / \mathrm{min}$ ).

For preparing $H A-A R F$ expression constructs, the ARF coding regions were amplified by PCR from Arabidopsis cDNA using $P f u$ DNA polymerase and gene-specific primers listed in Table S2. The DNA fragments were purified and digested with restriction enzymes, before they were cloned into a vector (based on pBI121) containing a $2 \times$ HA-tag sequence at the N-terminus [60] to make the $H A-A R F$ fusion. The $H A-A R F$ fragments were then cloned into a plant expression vector modified from pCambia1300 (http://www.cambia.org/daisy/cambia/585.html) behind the CaMV (cauliflower mosaic virus) $35 \mathrm{~S}$ promoter.

The constructs were used to transform WT Arabidopsis plants, using the infiltration method [61] with modifications [62]. Seeds from Agrobacterium-infiltrated plants were plated on agar plates containing hygromycin $(30 \mathrm{mg} / \mathrm{L})$. Hygromycin-resistant transformants were transferred to soil and genotyped using a primer specific to the HA sequence (CCCATACGATGTTCCAGAC) and a primer specific to the ARF gene (Table S2). Transgenic lines expressing the HA-ARF protein were further confirmed by western blotting (see below). At least two independent lines were analyzed initially. For most of the analysis, homozygous stable transgenic lines of $\mathrm{T} 2$ or later generations were used. 


\subsection{Seedling Growth and Treatments}

Seeds of transgenic HA-ARF and control Arabidopsis lines were sterilized, stored at $4{ }^{\circ} \mathrm{C}$ for two days and then plated on one-half MS agar plates $(100 \times 15 \mathrm{~mm})$ containing $0.5 \%$ sucrose and $0.7 \%$ agar. Plates were placed vertically in a plant tissue culture chamber $\left(20^{\circ} \mathrm{C}\right.$ constant, $16 / 8 \mathrm{~h}$ day/night photoperiod). Seedlings of 10-11 day old were used in general for various treatments.

For temperature treatments, plates with the seedlings were placed at the indicated temperatures. For other treatments, seedlings were transferred to treatment plates containing a piece of filter paper and $5 \mathrm{~mL}$ half-strength MS with or without a treatment reagent. The treatment plates with the plate lid on were placed in a box on a rotary platform with slow rotation. The treatment conditions used are: NAA (auxin), kinetin (cytokinin), (+)-ABA, ACC (1-aminocyclopropane-1-carboxylic acid), NaCl, mannitol, and temperature $\left(22^{\circ} \mathrm{C}, 4^{\circ} \mathrm{C}\right.$, and $\left.37^{\circ} \mathrm{C}\right)$ treatments. The concentrations for these reagents were selected based on previous testing done in our laboratory and they were specified in each figure. Following the treatment, about 25 seedlings from one plate were used to prepare one protein sample.

\subsection{Protein Extraction, Western Blotting, and Quantitative Analysis}

Plant tissues (seedlings) were homogenized with a plastic pestle in a $1.5 \mathrm{~mL}$ tube containing the protein extraction buffer ( $50 \mathrm{mM}$ Tris- $\mathrm{HCl} \mathrm{pH} \mathrm{8.0,} 200 \mathrm{mM} \mathrm{NaCl}, 10 \mathrm{mM}$ DTT (dithiothreitol), 1\% (v/v) Triton X-100, Sigma protease inhibitor cocktail (Sigma-Aldrich no. P9599, Oakville, ON, Canada)). Following centrifugation at $14,000 \times g$ for $10 \mathrm{~min}$ at $4{ }^{\circ} \mathrm{C}$, the supernatant was transferred into a fresh tube and centrifuged again for $5 \mathrm{~min}$. Bradford protein assay [63] was used (with Bradford reagent from Bio-Rad) to determine the total protein concentration, and the protein samples were stored at $-80{ }^{\circ} \mathrm{C}$ for further analysis.

Gel electrophoresis was performed in general as described [64] with a few modifications. Majority of analysis used min-gels (10\% resolving gels) prepared from the TGX Stain-Free FastCast Acrylamide Kit (Bio-Rad, no. 1610183, Hercules, CA, USA) and gel images were obtained using the Bio-Rad Gel DocXR+ imaging system. Some gels were prepared using regular acrylamide solution (29:1 mix). Following electrophoresis, proteins were transferred onto PVDF membrane (Bio-Rad) using a Bio-Rad Trans-Blot apparatus at a constant voltage of $25 \mathrm{~V}$ for $12 \mathrm{~h}$ in $4{ }^{\circ} \mathrm{C}$.

Western blotting was performed as described [64]. For detecting HA-ARF fusion proteins, mouse monoclonal anti-HA antibodies (YEASEN no. 30701ES20, Beijing, China or Santa Cruz no. sc-7392, Dallas, TX, USA) were used. The loading control used a mouse monoclonal anti-actin antibody (Abbkine no. A01050, Wuhan, China; 1:5000). For quantitative analysis, the intensity of each protein band was measured using Bio-Rad Image lab software 15.2.1. The relative band intensity was obtained with the average of the control treatment set at 1.0. Student's $t$-test (two-tail, unequal varience) was used to analyze the difference between the control and treatment values.

\subsection{HA-ARF Protein Pulldown by Immunoprecipitation}

For HA-ARF6 protein pulldown, total protein extract $(600 \mu \mathrm{g})$ was incubated with anti-HA agarose beads (Sigma-Aldrich, Oakville, ON, Canada) at $4{ }^{\circ} \mathrm{C}$ for $1 \mathrm{~h}$ (on a tumbler). The beads were washed twice with the wash buffer $(10 \mathrm{mM}$ Tris- $\mathrm{HCl}$ at $\mathrm{pH} 8.0,5 \mathrm{mM} \mathrm{NaCl}, 0.05 \%$ Tween, $0.5 \mathrm{mM}$ dithiothreitol and $0.5 \mathrm{mg} \mathrm{mL}^{-1} \mathrm{BSA}$ ). The bound proteins were eluted with $1 \mathrm{mg} / \mathrm{mL}$ HA peptide (GenScript, Piscataway, NJ, USA), added with SDS sample buffer, and heat-treated at $95^{\circ} \mathrm{C}$ for $5 \mathrm{~min}$. The samples were then used in electrophoresis and western blot analysis. HA-ARF6 and ubiquitinated ARF6 were detected using anti-HA (Santa Cruz no. sc-7392) and anti-Ub (Cell Signaling Technology no. P4D1, Danvers, MA, USA) antibodies respectively, and a horseradish peroxidase-conjugated goal anti-mouse antibody (Bio-Rad). The signal was visualized with ECL Plus reagent (Cytiva-formerly GE Life Sciences, Mississauga, ON, Canada) according to the manufacturer's instructions. 


\subsection{RNA Isolation and PCR Analysis}

Total RNA samples were isolated from seedlings using the Invitrogen TRIzol reagent (Fisher Scientific) following the manufacturer's instructions. The RNA concentration was measured with a NanoVue Plus Spectrophotometer (Cytiva-formerly GE Life Sciences, Marlborough, MA, USA) following the manufacturer's instructions. cDNAs were synthesized using the Takara PrimeScript RT reagent Kit with gDNA Eraser and $1.0 \mu \mathrm{g}$ total RNA in $20 \mu \mathrm{L}$ following the manufacturer's instructions.

For RT-PCR, the HA-ARF CDNA was diluted by one-third with sterile water and $1.0 \mu \mathrm{L}$ diluted cDNA was used in $20 \mu \mathrm{L}$ PCR reaction with $250 \mu \mathrm{M}$ each of the primers. The PCR conditions were: $95{ }^{\circ} \mathrm{C}$ for $1 \mathrm{~min}$, then 34 cycles of $94{ }^{\circ} \mathrm{C}$ for $50 \mathrm{~s}, 55^{\circ} \mathrm{C}$ for $50 \mathrm{~s}$, and $72{ }^{\circ} \mathrm{C}$ for $1 \mathrm{~min}$, and a final extension $72{ }^{\circ} \mathrm{C}$ for $1 \mathrm{~min}$. HA-ARF6 was amplified using a primer specific to the HA-sequence (5'-CCCATACGATGTTCCAGAC) and reverse primer specific to ARF6 (5'-TATCATGCAGATCCCTCGC). The control At4g33380 was amplified with the forward (5'-ATGAGAAGCTGGAGGAAGC) and reverse (5'-TCAAGCCGTTACAACACC) primers. For qPCR, the reactions were performed in $20 \mu \mathrm{L}$, using $10 \mu \mathrm{L}$ $2 \times$ iQ SYBR Green Supermix (Bio-Rad), $1.0 \mathrm{uL}$ cDNA and $200 \mu \mathrm{M}$ each of the primers, and run in the Bio-Rad CFX96 Real-Time PCR System. The threshold cycle $(\mathrm{Ct})$ values were generated with the Bio-Rad CFX Manager Software (Version 3.0).

Supplementary Materials: The following are available online at http://www.mdpi.com/1422-0067/21/24/9437/s1.

Author Contributions: H.W. (Hong Wang) and H.W. (Hong Wu) initiated and supervised the project. K.L. and S.W. performed the experimental work and data analysis. H.W. (Hong Wang) wrote the manuscript with input from other authors. All authors have read and agreed to the published version of the manuscript.

Funding: This research was supported by the Natural Sciences and Engineering Research Council of Canada (Discovery grant no. RGPIN-2018-05834) to H. Wang and National Natural Science Foundation of China (grant no. 31870172) to H. Wu. K.L. was supported by a scholarship from the Chinese Scholarship Council and a scholarship from the Department of Education of Guangdong Province.

Conflicts of Interest: The authors declare no conflict of interest.

\section{References}

1. Mockaitis, K.; Estelle, M. Auxin receptors and plant development: A new signaling paradigm. Annu. Rev. Cell Dev. Biol. 2008, 24, 55-80. [CrossRef]

2. Weijers, D.; Wagner, D. Transcriptional Responses to the Auxin Hormone. Annu. Rev. Plant Biol. 2016, 67, 539-574. [CrossRef] [PubMed]

3. Finet, C.; Berne-Dedieu, A.; Scutt, C.P.; Marletaz, F. Evolution of the ARF gene family in land plants: Old domains, new tricks. Mol. Biol. Evol. 2013, 30, 45-56. [CrossRef] [PubMed]

4. Guilfoyle, T.J.; Hagen, G. Auxin response factors. Curr. Opin. Plant Biol. 2007, 10, 453-460. [CrossRef] [PubMed]

5. Chandler, J.W. Auxin response factors. Plant Cell Environ. 2016, 39, 1014-1028. [CrossRef]

6. Ulmasov, T.; Hagen, G.; Guilfoyle, T.J. Activation and repression of transcription by auxin-response factors. Proc. Natl. Acad. Sci. USA 1999, 96, 5844-5849. [CrossRef] [PubMed]

7. Tiwari, S.B.; Hagen, G.; Guilfoyle, T. The roles of auxin response factor domains in auxin-responsive transcription. Plant Cell 2003, 15, 533-543. [CrossRef] [PubMed]

8. Kato, H.; Nishihama, R.; Weijers, D.; Kohchi, T. Evolution of nuclear auxin signaling: Lessons from genetic studies with basal land plants. J. Exp. Bot. 2018, 69, 291-301. [CrossRef]

9. Roosjen, M.; Paque, S.; Weijers, D. Auxin Response Factors: Output control in auxin biology. J. Exp. Bot. 2018, 69, 179-188. [CrossRef]

10. Ulmasov, T.; Hagen, G.; Guilfoyle, T.J. ARF1, a transcription factor that binds to auxin response elements. Science 1997, 276, 1865-1868. [CrossRef]

11. Nanao, M.H.; Vinos-Poyo, T.; Brunoud, G.; Thevenon, E.; Mazzoleni, M.; Mast, D.; Laine, S.; Wang, S.; Hagen, G.; Li, H.; et al. Structural basis for oligomerization of auxin transcriptional regulators. Nat. Commun. 2014, 5, 3617. [CrossRef] [PubMed] 
12. Korasick, D.A.; Westfall, C.S.; Lee, S.G.; Nanao, M.H.; Dumas, R.; Hagen, G.; Guilfoyle, T.J.; Jez, J.M.; Strader, L.C. Molecular basis for AUXIN RESPONSE FACTOR protein interaction and the control of auxin response repression. Proc. Natl. Acad. Sci. USA 2014, 111, 5427-5432. [CrossRef] [PubMed]

13. Guilfoyle, T.J. The PB1 domain in auxin response factor and Aux/IAA proteins: A versatile protein interaction module in the auxin response. Plant Cell 2015, 27, 33-43. [CrossRef] [PubMed]

14. Luo, J.; Zhou, J.J.; Zhang, J.Z. Aux/IAA Gene Family in Plants: Molecular Structure, Regulation, and Function. Int. J. Mol. Sci. 2018, 19, 259. [CrossRef] [PubMed]

15. Vernoux, T.; Brunoud, G.; Farcot, E.; Morin, V.; Van den Daele, H.; Legrand, J.; Oliva, M.; Das, P.; Larrieu, A.; Wells, D.; et al. The auxin signalling network translates dynamic input into robust patterning at the shoot apex. Mol. Syst. Biol. 2011, 7, 508. [CrossRef]

16. Piya, S.; Shrestha, S.K.; Binder, B.; Stewart, C.N., Jr.; Hewezi, T. Protein-protein interaction and gene co-expression maps of ARFs and Aux/IAAs in Arabidopsis. Front. Plant Sci. 2014, 5, 744. [CrossRef]

17. Kelley, D.R.; Arreola, A.; Gallagher, T.L.; Gasser, C.S. ETTIN (ARF3) physically interacts with KANADI proteins to form a functional complex essential for integument development and polarity determination in Arabidopsis. Development 2012, 139, 1105-1109. [CrossRef]

18. Varaud, E.; Brioudes, F.; Szecsi, J.; Leroux, J.; Brown, S.; Perrot-Rechenmann, C.; Bendahmane, M. AUXIN RESPONSE FACTOR8 regulates Arabidopsis petal growth by interacting with the bHLH transcription factor BIGPETALp. Plant Cell 2011, 23, 973-983. [CrossRef] [PubMed]

19. Oh, E.; Zhu, J.Y.; Bai, M.Y.; Arenhart, R.A.; Sun, Y.; Wang, Z.Y. Cell elongation is regulated through a central circuit of interacting transcription factors in the Arabidopsis hypocotyl. Elife 2014, 3, e03031. [CrossRef]

20. Li, S.B.; Xie, Z.Z.; Hu, C.G.; Zhang, J.Z. A Review of Auxin Response Factors (ARFs) in Plants. Front. Plant Sci. 2016, 7, 47. [CrossRef]

21. Okushima, Y.; Overvoorde, P.J.; Arima, K.; Alonso, J.M.; Chan, A.; Chang, C.; Ecker, J.R.; Hughes, B.; Lui, A.; Nguyen, D.; et al. Functional genomic analysis of the AUXIN RESPONSE FACTOR gene family members in Arabidopsis thaliana: Unique and overlapping functions of ARF7 and ARF19. Plant Cell 2005, 17, 444-463. [CrossRef] [PubMed]

22. Li, H.; Johnson, P.; Stepanova, A.; Alonso, J.M.; Ecker, J.R. Convergence of signaling pathways in the control of differential cell growth in Arabidopsis. Dev. Cell 2004, 7, 193-204. [CrossRef]

23. Harper, R.M.; Stowe-Evans, E.L.; Luesse, D.R.; Muto, H.; Tatematsu, K.; Watahiki, M.K.; Yamamoto, K.; Liscum, E. The NPH4 locus encodes the auxin response factor ARF7, a conditional regulator of differential growth in aerial Arabidopsis tissue. Plant Cell 2000, 12, 757-770. [CrossRef] [PubMed]

24. Hardtke, C.S.; Berleth, T. The Arabidopsis gene MONOPTEROS encodes a transcription factor mediating embryo axis formation and vascular development. EMBO J. 1998, 17, 1405-1411. [CrossRef] [PubMed]

25. Tian, C.E.; Muto, H.; Higuchi, K.; Matamura, T.; Tatematsu, K.; Koshiba, T.; Yamamoto, K.T. Disruption and overexpression of auxin response factor 8 gene of Arabidopsis affect hypocotyl elongation and root growth habit, indicating its possible involvement in auxin homeostasis in light condition. Plant J. 2004, 40, 333-343. [CrossRef] [PubMed]

26. Wang, S.; Tiwari, S.B.; Hagen, G.; Guilfoyle, T.J. AUXIN RESPONSE FACTOR7 restores the expression of auxin-responsive genes in mutant Arabidopsis leaf mesophyll protoplasts. Plant Cell 2005, 17, 1979-1993. [CrossRef]

27. Gutierrez, L.; Bussell, J.D.; Pacurar, D.I.; Schwambach, J.; Pacurar, M.; Bellini, C. Phenotypic plasticity of adventitious rooting in Arabidopsis is controlled by complex regulation of AUXIN RESPONSE FACTOR transcripts and microRNA abundance. Plant Cell 2009, 21, 3119-3132. [CrossRef]

28. Reed, J.W.; Wu, M.F.; Reeves, P.H.; Hodgens, C.; Yadav, V.; Hayes, S.; Pierik, R. Three Auxin Response Factors Promote Hypocotyl Elongation. Plant Physiol. 2018, 178, 864-875. [CrossRef]

29. Nagpal, P.; Ellis, C.M.; Weber, H.; Ploense, S.E.; Barkawi, L.S.; Guilfoyle, T.J.; Hagen, G.; Alonso, J.M.; Cohen, J.D.; Farmer, E.E.; et al. Auxin response factors ARF6 and ARF8 promote jasmonic acid production and flower maturation. Development 2005, 132, 4107-4118. [CrossRef]

30. Tabata, R.; Ikezaki, M.; Fujibe, T.; Aida, M.; Tian, C.E.; Ueno, Y.; Yamamoto, K.T.; Machida, Y.; Nakamura, K.; Ishiguro, S. Arabidopsis auxin response factor6 and 8 regulate jasmonic acid biosynthesis and floral organ development via repression of class 1 KNOX genes. Plant Cell Physiol. 2009, 51, 164-175. [CrossRef] 
31. Huang, K.L.; Ma, G.J.; Zhang, M.L.; Xiong, H.; Wu, H.; Zhao, C.Z.; Liu, C.S.; Jia, H.X.; Chen, L.; Kjorven, J.O.; et al. The ARF7 and ARF19 Transcription Factors Positively Regulate PHOSPHATE STARVATION RESPONSE1 in Arabidopsis Roots. Plant Physiol. 2018, 178, 413-427. [CrossRef] [PubMed]

32. Ellis, C.M.; Nagpal, P.; Young, J.C.; Hagen, G.; Guilfoyle, T.J.; Reed, J.W. AUXIN RESPONSE FACTOR1 and AUXIN RESPONSE FACTOR2 regulate senescence and floral organ abscission in Arabidopsis thaliana. Development 2005, 132, 4563-4574. [CrossRef] [PubMed]

33. Promchuea, S.; Zhu, Y.; Chen, Z.; Zhang, J.; Gong, Z. ARF2 coordinates with PLETHORAs and PINs to orchestrate ABA-mediated root meristem activity in Arabidopsis. J. Integr. Plant Biol. 2017, 59, $30-43$. [CrossRef]

34. Wang, J.W.; Wang, L.J.; Mao, Y.B.; Cai, W.J.; Xue, H.W.; Chen, X.Y. Control of root cap formation by MicroRNA-targeted auxin response factors in Arabidopsis. Plant Cell 2005, 17, 2204-2216. [CrossRef] [PubMed]

35. Qiao, M.; Zhao, Z.; Song, Y.; Liu, Z.; Cao, L.; Yu, Y.; Li, S.; Xiang, F. Proper regeneration from in vitro cultured Arabidopsis thaliana requires the microRNA-directed action of an auxin response factor. Plant J. 2012, 71, 14-22. [CrossRef] [PubMed]

36. Liu, Z.; Li, J.; Wang, L.; Li, Q.; Lu, Q.; Yu, Y.; Li, S.; Bai, M.Y.; Hu, Y.; Xiang, F. Repression of callus initiation by the miRNA-directed interaction of auxin-cytokinin in Arabidopsis thaliana. Plant J. 2016, 87, 391-402. [CrossRef] [PubMed]

37. Han, S.; Hwang, I. Integration of multiple signaling pathways shapes the auxin response. J. Exp. Bot. 2018, 69, 189-200. [CrossRef]

38. Rademacher, E.H.; Moller, B.; Lokerse, A.S.; Llavata-Peris, C.I.; van den Berg, W.; Weijers, D. A cellular expression map of the Arabidopsis AUXIN RESPONSE FACTOR gene family. Plant J. 2011, 68, 597-606. [CrossRef]

39. Vert, G.; Walcher, C.L.; Chory, J.; Nemhauser, J.L. Integration of auxin and brassinosteroid pathways by Auxin Response Factor 2. Proc. Natl. Acad. Sci. USA 2008, 105, 9829-9834. [CrossRef]

40. Zhao, S.; Zhang, M.L.; Ma, T.L.; Wang, Y. Phosphorylation of ARF2 Relieves Its Repression of Transcription of the K+ Transporter Gene HAK5 in Response to Low Potassium Stress. Plant Cell 2016, 28, 3005-3019. [CrossRef]

41. Cho, H.; Ryu, H.; Rho, S.; Hill, K.; Smith, S.; Audenaert, D.; Park, J.; Han, S.; Beeckman, T.; Bennett, M.J.; et al. A secreted peptide acts on BIN2-mediated phosphorylation of ARFs to potentiate auxin response during lateral root development. Nat. Cell. Biol. 2014, 16, 66-76. [CrossRef] [PubMed]

42. Orosa-Puente, B.; Leftley, N.; von Wangenheim, D.; Banda, J.; Srivastava, A.K.; Hill, K.; Truskina, J.; Bhosale, R.; Morris, E.; Srivastava, M.; et al. Root branching toward water involves posttranslational modification of transcription factor ARF7. Science 2018, 362, 1407-1410. [CrossRef] [PubMed]

43. Salmon, J.; Ramos, J.; Callis, J. Degradation of the auxin response factor ARF1. Plant J. 2008, 54, 118-128. [CrossRef] [PubMed]

44. Richter, R.; Behringer, C.; Zourelidou, M.; Schwechheimer, C. Convergence of auxin and gibberellin signaling on the regulation of the GATA transcription factors GNC and GNL in Arabidopsis thaliana. Proc. Natl. Acad. Sci. USA 2013, 110, 13192-13197. [CrossRef]

45. Lakehal, A.; Chaabouni, S.; Cavel, E.; Le Hir, R.; Ranjan, A.; Raneshan, Z.; Novak, O.; Pacurar, D.I.; Perrone, I.; Jobert, F.; et al. A Molecular Framework for the Control of Adventitious Rooting by TIR1/AFB2-Aux/IAA-Dependent Auxin Signaling in Arabidopsis. Mol. Plant 2019, 12, 1499-1514. [CrossRef] [PubMed]

46. Sah, S.K.; Reddy, K.R.; Li, J. Abscisic Acid and Abiotic Stress Tolerance in Crop Plants. Front. Plant Sci. 2016, 7, 571. [CrossRef] [PubMed]

47. Muday, G.K.; Rahman, A.; Binder, B.M. Auxin and ethylene: Collaborators or competitors? Trends Plant Sci. 2012, 17, 181-195. [CrossRef]

48. O’Brien, J.A.; Benkova, E. Cytokinin cross-talking during biotic and abiotic stress responses. Front. Plant Sci. 2013, 4, 451. [CrossRef]

49. Liu, J.; Moore, S.; Chen, C.; Lindsey, K. Crosstalk Complexities between Auxin, Cytokinin, and Ethylene in Arabidopsis Root Development: From Experiments to Systems Modeling, and Back Again. Mol. Plant 2017, 10, 1480-1496. [CrossRef] 
50. Liu, X.; Zhang, H.; Zhao, Y.; Feng, Z.; Li, Q.; Yang, H.Q.; Luan, S.; Li, J.; He, Z.H. Auxin controls seed dormancy through stimulation of abscisic acid signaling by inducing ARF-mediated ABI3 activation in Arabidopsis. Proc. Natl. Acad. Sci. USA 2013, 110, 15485-15490. [CrossRef]

51. Tian, R.; Wang, F.; Zheng, Q.; Niza, V.; Downie, A.B.; Perry, S.E. Direct and indirect targets of the arabidopsis seed transcription factor ABSCISIC ACID INSENSITIVE3. Plant J. 2020, 103, 1679-1694. [CrossRef] [PubMed]

52. Meng, L.S.; Wang, Z.B.; Yao, S.Q.; Liu, A. The ARF2-ANT-COR15A gene cascade regulates ABA-signaling-mediated resistance of large seeds to drought in Arabidopsis. J. Cell Sci. 2015, 128, 3922-3932. [CrossRef]

53. Kang, C.; He, S.; Zhai, H.; Li, R.; Zhao, N.; Liu, Q. A Sweetpotato Auxin Response Factor Gene (IbARF5) Is Involved in Carotenoid Biosynthesis and Salt and Drought Tolerance in Transgenic Arabidopsis. Front. Plant Sci. 2018, 9, 1307. [CrossRef] [PubMed]

54. Bouzroud, S.; Gasparini, K.; Hu, G.; Barbosa, M.A.M.; Rosa, B.L.; Fahr, M.; Bendaou, N.; Bouzayen, M.; Zsogon, A.; Smouni, A.; et al. Down Regulation and Loss of Auxin Response Factor 4 Function Using CRISPR/Cas9 Alters Plant Growth, Stomatal Function and Improves Tomato Tolerance to Salinity and Osmotic Stress. Genes 2020, 11, 272. [CrossRef] [PubMed]

55. Nag, R.; Maity, M.K.; Dasgupta, M. Dual DNA binding property of ABA insensitive 3 like factors targeted to promoters responsive to ABA and auxin. Plant Mol. Biol. 2005, 59, 821-838. [CrossRef] [PubMed]

56. Wang, L.; Hua, D.; He, J.; Duan, Y.; Chen, Z.; Hong, X.; Gong, Z. Auxin Response Factor2 (ARF2) and its regulated homeodomain gene HB33 mediate abscisic acid response in Arabidopsis. PLoS Genet. 2011, 7, e1002172. [CrossRef] [PubMed]

57. Shibasaki, K.; Uemura, M.; Tsurumi, S.; Rahman, A. Auxin response in Arabidopsis under cold stress: Underlying molecular mechanisms. Plant Cell 2009, 21, 3823-3838. [CrossRef] [PubMed]

58. Li, J.; Dai, X.; Zhao, Y. A role for auxin response factor 19 in auxin and ethylene signaling in Arabidopsis. Plant Physiol. 2006, 140, 899-908. [CrossRef]

59. Perilli, S.; Perez-Perez, J.M.; Di Mambro, R.; Peris, C.L.; Diaz-Trivino, S.; Del Bianco, M.; Pierdonati, E.; Moubayidin, L.; Cruz-Ramirez, A.; Costantino, P.; et al. Retinoblastoma-related protein stimulates cell differentiation in the Arabidopsis root meristem by interacting with cytokinin signaling. Plant Cell 2013, 25, 4469-4478. [CrossRef]

60. Li, Q.; Shi, X.Z.; Ye, S.J.; Wang, S.; Chan, R.; Harkness, T.; Wang, H. A short motif in Arabidopsis CDK inhibitor ICK1 decreases the protein level, probably through a ubiquitin-independent mechanism. Plant J. 2016, 87, 617-628. [CrossRef]

61. Bechtold, N.; Ellis, J.; Pelletier, G. In planta Agrobacterium mediated gene transfer by infiltration of adult Arabidopsis thaliana plants. C. R. Acad. Sci. Paris Sci. Life Sci. 1993, 316, 1194-1199.

62. Wang, H.; Zhou, Y.; Gilmer, S.; Whitwill, S.; Fowke, L.C. Expression of the plant cyclin-dependent kinase inhibitor ICK1 affects cell division, plant growth and morphology. Plant J. 2000, 24, 613-623. [CrossRef] [PubMed]

63. Bradford, M.M. A rapid and sensitive method for the quantitation of microgram quantities of protein utilizing the principle of protein-dye binding. Anal. Biochem. 1976, 72, 248-254. [CrossRef]

64. Zhou, Y.; Li, G.; Brandizzi, F.; Fowke, L.C.; Wang, H. The plant cyclin-dependent kinase inhibitor ICK1 has distinct functional domains for in vivo kinase inhibition, protein instability and nuclear localization. Plant J. 2003, 35, 476-489. [CrossRef]

Publisher's Note: MDPI stays neutral with regard to jurisdictional claims in published maps and institutional affiliations.

(C) 2020 by the authors. Licensee MDPI, Basel, Switzerland. This article is an open access article distributed under the terms and conditions of the Creative Commons Attribution (CC BY) license (http://creativecommons.org/licenses/by/4.0/). 